\title{
Technology Studies
}

online multimedia journal

Культура и технологии

электронный мультимедийный журнал

Journal Homepage: http://cat.ifmo.ru

ISSN 2587-800X

Адрес статьи / To link this article: $\underline{\text { http://cat.itmo.ru/ru/2021/v6-i1/262 }}$

\section{Digital краеведение: моделирование национального регионального наследия библиотек в электронной среде (на примере фонда «Петербурговедение»)}

\author{
Е.В. Смолина \\ Президентская библиотека имени Б.Н. Ельцина, Россия \\ smolinaeprlib.ru
}

\begin{abstract}
Аннотация: В статье обозначены проблемы освоения библиотеками электронной среды, подчеркнута недостаточность научных исследований для получения конвергентного знания как основы принятия управленческих решений в библиотечном деле по созданию электронных коллекций «национальной памяти». Предложен метод моделирования как один из способов представления национального краевого наследия в электронной среде. Моделирование строится с учетом новых свойств библиотек в электронной среде. Основа моделирования «репертуар русской книги». Показана логика моделирования на примере фонда «Петербурговедение».
\end{abstract}

Ключевые слова: digital краеведение, моделирование, петербурговедение, электронная среда, региональное наследие библиотек, конвергентное знание, культура как фактор национальной безопасности

По словам А.А. Пелипенко «...феномен Интернета - это не просто изобретение технологической эпохи, а системный фактор культуры. Интернет - одна из причин культурноантропологической эволюции в современности, меняющая ментальный тип человека. Если это так, то человечество стоит на пороге не только культурной, но антропологической революции, масштаб и последствия которой сопоставимы с самим выходом человека из природного царства...» $[1$, с.167].

Электронная среда обладает различными свойствами, которые как отрицательно, так и положительно могут влиять на жизнедеятельность человека. Отметим одно важное положительное качество электронной среды - это возможность представить, сделать доступным национальное наследие для населения всей страны.

В своем послании Федеральному собранию в 2018 году Президент России В.В. Путин также обращает внимание на значение национальной культуры: «Сохранить свою идентичность крайне важно в бурный век технологических перемен, и здесь невозможно переоценить роль культуры, которая является нашим общенациональным цивилизационным кодом, раскрывает в человеке созидательные начала» [2]. 
«Осознание факта главенства культуры во всей системе жизнедеятельности превращает ее из феномена, традиционно соотносимого по преимуществу со сферой прекрасного, в главный фактор современного развития - в фактор национальной безопасности. Именно культура становится главной целью современных войн - консциентальных, информационных, сетецентрических, кибер-войн... Победить в этой войне - значит, защитить свои метафизические ценности, свой образ мира и образ будущего. При этом сама культура в XXI веке выступает в качестве одного из 4 основных, стратегически важных факторов национальной безопасности не только России, решение этой проблемы определяет будущее всего мира» [3, с. 6].

В России национальная культура признана фактором национальной безопасности страны. В «Стратегии национальной безопасности Российской Федерации до 2020 г.» к стратегическим целям обеспечения национальной безопасности в области культуры в пункте 79 Стратегии отнесены: «обеспечение расширенного доступа широких слоев населения к лучшим образцам отечественной и зарубежной культуры и искусства путем создания современных территориально распределенных информационных фондов, которые позволяют аккумулировать информацию культурной сферы и сделать ее доступной на уровне субъектов Российской Федерации» [4].

\section{Значение научного знания для развития электронных библиотек}

Факторами мирового развития становятся: скорость, объем и широта распространения информации. На этой основе активно формируется цифровая экономика [5].

Сегодня необходимо констатировать, что жизнедеятельность библиотек в электронной среде очень мало изучена. Очень мало научных исследований и недостаточно научнометодических разработок для организации работы с читателями в электронной среде. Кроме того, в настоящее время научно-исследовательская деятельность даже не включается в «государственное задание» для федеральных библиотек.

Практически нет прогностических исследований, которые бы показали тот образ будущей библиотеки в электронной среде, того «должного», к которому надо стремиться, куда мы идем, а без образа будущего (модель) трудно прописать конкретные шаги, движение (стратегию), достижения этого результата [6].

Большинство идей, которые сегодня воплощаются в практике работы библиотек в электронной среде, созданы IT-специалистами, а не библиотекарями. Стоит согласиться с заместителем председателя Межправительственного совета и председателем Российского комитета Программы ЮНЕСКО «Информация для всех», президентом Межрегионального центра библиотечного сотрудничества Е.И. Кузьминым, который подчеркнул, что новые технологии становятся драйверами перемен в сфере культуры. Они серьезно влияют и на библиотечное обслуживание. Во всем мире в корне пересматриваются технологии и методы библиотечной работы, связанные с комплектованием, сохранением, обработкой и формами обслуживания». Эти изменения надо тщательно отслеживать, изучать, анализировать, своевременно и адекватно на них реагировать, уточняя роли библиотек. В этих условиях надо усиливать библиотечную науку и методическую работу (из предвыборной речи 15 мая 2017 года на Всероссийском библиотечном конгрессе: XXII Ежегодной Конференции Российской библиотечной ассоциации в Красноярске).

Сегодня условием освоения электронной среды библиотеками, становится необходимость наличия конвергентных знаний как результатов междисциплинарных исследований для управления процессами организации не просто «доступа», а библиотечного обслуживания на основе электронных ресурсов библиотеки. Это задача для библиотековедов, ученых отрасли. «Мы живем в такое время, когда высокотехнологичное пространство производит в научной и образовательной сфере тектонические изменения, это уже другой мир. Осмысление таких систем требует конвергенции, исследований на стыке технического и социогуманитарного знания», сказал Михаил Ковальчук, президент НИЦ «Курчатовский институт» [7].

Таким образом, с нашей точки зрения, самый сильный удар по развитию библиотек в электронной среде будет нанесен именно отсутствием научных знаний и информации для принятия управленческих решений по освоению библиотеками электронной среды. Именно от того, какая система знаний, какие представления и прогнозы, какая аксиология будут положены в

International Culture \& Technology Studies, Vol. 6, No. 1 
основу «Концепции развития библиотечного дела» в стране будет зависеть будущее развитие всей библиотечной сферы, в том числе и стратегии освоения электронной среды.

\section{Проблемы освоения библиотеками электронной среды}

В России процесс освоения электронной среды библиотеками, представление национального наследия связан с несколькими обстоятельствами.

Во-первых, нет общей концепции единого электронного пространства библиотек России, принятой на уровне Правительства РФ.

Библиотеки относятся к экономике «общественного блага», являются социальным институтом, культурное значение их для развития страны декларируется на государственном уровне. Так, «Стратегия государственной культурной политики на период до 2030 г.» (утверждена распоряжением Правительства российской Федерации от 29 февраля 2016 г. № 26-p), «Стратегия развития информационного общества Российской Федерации от 9 мая 2017 г. № 203» говорят о необходимости формирования «единого российского электронного пространства знаний». Итогом Парламентских слушаний 13 февраля 2018 года в Москве на тему «Цифровизация в сфере культуры. Законодательство и правоприменительная практика», которые состоялись в Госдуме по инициативе Комитета по культуре, стали рекомендации участников слушаний правительству РФ, Минкультуры и органам государственной власти субъектов Российской Федерации. Правительству рекомендовано, в частности, дополнить цели программы «Цифровая экономика Российской Федерации» целью формирования единого российского электронного пространства знаний на основе оцифрованных книжных, архивных, музейных фондов, собранных в Национальную электронную библиотеку (НЭБ) и национальные электронные архивы по различным отраслям знания и сферам творческой деятельности» $[8$, с. 1$]$.

Даже тот нарратив, те языковые стратегии, которые сегодня используются для описания электронной среды в России, вызывают много вопросов.

Здесь уже само понятие «единое российское электронное пространство знаний» выглядит не как термин, понятие, имеющие четкое содержание, а, скорее, как имя собственное, за которым может стоять все, что угодно. Анализируя это название можно сказать, что это пространство не «единое», так как оно планируется только на основе НЭБ и ее точек доступа. Оно и не российское, а американское, так как существует в сети Интернет. Это и не пространство «знаний», так как знание может быть атрибутом только субъекта, то есть одушевлённого существа, а не «пространства» [9]. Если бы в основу концепции НЭБ была положена социокультурная модель, отражающая целостное понимание российского электронного пространства и роли библиотек в нем, прежде всего, сформулирован и эксплицирован её культурный смысл как социального национального института, который реализует культурно значимую конкретную работу на уровне всего государства, многие вопросы были бы сняты. Например, как соотносится НЭБ и Президентская библиотека, которая создана изначально как электронная национальная библиотека и также имеет точки доступа к своему фонду в регионах страны. Непонятно также, что такое «национальные электронные архивы по различным отраслям знания и сферам творческой деятельности» и т.д. Список вопросов можно было бы продолжить.

Сегодня в мире уже существует достаточно примеров создания национальных электронных коллекций, национальной памяти той или иной страны. Например, это такие коллекции как «Память Америки», «Память Испании», DEF (Дания), Библиотека и архив Канады, Gallica (Франция), FinLib (Финляндия) и т.д. Россия имеет значительное культурное наследие, но до сих пор нет проекта, который бы представил для нации ее национальную культуру в электронной среде, электронной «Памяти России» даже нет в проекте. Это вызывает удивление.

Для встраивания в электронную среду ресурс «Культура России» должен быть полноценной поисковой системой наряду с Google, Rambler, Yandex, Youtube и т.д., а не находиться внутри них. По мнению Владимира Миронова, экс-декана философского факультета МГУ, Интернет - это такой «информационный мешок», куда скидываются разные информационные ресурсы, они интегрируются друг с другом случайным образом как получится, и эта интеграция не всегда со знаком плюс [10]. 
Интернет - это стихия сущего, а культура - организованное должное. В Интернете сетевые модели преобладают, а культура - это всегда иерархическая модель [11]. Электронная среда творит симулякры, где трудно отличить настоящее от иллюзии, а в библиотеках экспертный отбор документов в фонд. Интернет формирует транснациональные глобальные культурные общности [12], место локальной национальной культуры заменяет глобальная культура.

Во-вторых, библиотеки не институционализированы в электронной среде полностью.

Библиотеки относятся к экономике «общественного блага», являются социальным институтом. Важное значение их развития декларируется на государственном уровне.

В традиционной среде библиотеки, архивы и музеи отнесены, являются социальным институтом [13], относятся к общественному благу, финансируются из государственного сектора экономики. Если учреждения осуществляют свою деятельность в статусе социального института, то их программа действий осуществляется на основе государственных политических решений в рамках культурной политики государства.

В традиционной среде учреждения культуры представлены как отдельные учреждения: библиотеки, музеи, архивы и т.д., а в электронной среде их фонды могут быть объединены в один. То есть электронная среда позволяет собирать комплексный ресурс из различных видов и типов документов, которые в традиционном виде хранятся в различных учреждениях. Сегодня не создано нормативно-правового механизма комплектования электронных библиотек на базе различных учреждений (нет политического решения в рамках культурной политики государства). Каждая организация оцифровывает «свои» фонды и с большой неохотой отдает их в другие электронные библиотеки. Как правило, решения принимаются на уровне директоров учреждений - хранителей библиотечных, архивных, музейных документов, кто даст, а кто-то и не даст, объясняя это тем, что «это же “наши ресурсы”, как мы можем их отдавать другим, сами будем цифровать для своей электронной библиотеки...» и т.д. Таким образом, в электронной среде институционализация библиотек «не работает» до конца. Финансирует оцифровку фондов государство, а решения по созданию совместных электронных коллекций принимаются на уровне отдельных директоров отдельных учреждений культуры.

В-третьих, отсутствие научно-методического осмысления библиотечного обслуживания в электронной среде.

Еще раз подчеркнем связь между качеством принимаемых решений и наличием и качеством используемых для этого научных профессиональных знаний и информации.

Таким образом, особую роль в разработке направлений развития библиотечного дела в электронной среде играют результаты научной и научно-методической деятельности, результаты работы профессионального сообщества библиотечной отрасли, которые могут стать основой принятия управленческих государственных решений.

\section{Новые свойства библиотек в электронной среде}

Еще один вопрос, который требует научной разработки, это - новые свойства библиотек в электронной среде [14].

В электронной среде у библиотек появляются новые свойства, два из них - это комплексность (возможность собрать разные виды и типы документов) и целостность (полнота), возможность формировать «целостные коллекции», то есть коллекции, характеризующиеся значительной степенью содержательной полноты фонда из различных видов и типов документов. Благодаря возможностям электронной среды, такой принцип комплектования как «полнота представления материала» теперь может стать характеристикой не только собраний национальных библиотек, но быть реализован и на уровне одной тематической коллекции.

Возможность собрать целостный ресурс, обеспечить полноту коллекции документов для краеведческих ресурсов особенно важно, так как документы могут храниться в разных учреждениях: библиотеках, архивах и музеях разных городов и стран. Электронная среда позволит собрать краеведческие ресурсы в их полноте, представив информацию о родном регионе, крае,

International Culture \& Technology Studies, Vol. 6, No. 1 
городе, о важнейших событиях, персоналиях жителей той или иной области, города, района и т.д., выстроенную в соответствии с концептуальной конкретизацией той или иной области в краеведческой коллекции.

Свойство «целостность или полнота коллекции», которое появляется у библиотек в электронной среде, может быть реализовано в различных подходах к формированию электронного фонда. Например, собрать все о персоне, которая имеет отношению к месту. Коллекция «Все о М.Д. Скобелеве» будет актуальна для Рязанской ОУНБ, «Все о И.А. Гончарове» - для Ульяновской ОНБ (например, «Архив И.А. Гончарова» находится в РНБ в Петербурге, а в электронном виде он сможет вернуться на родину) и т.д., и т.п. Эти коллекции могли бы включить электронные копии всех ресурсов, которые хранятся в фондах других учреждений культуры по всей стране: библиотеках, архивах и музеях, но имеют прямое отношение к культурному наследию конкретного края.

И такой опыт уже существует в мире, например, проект Библиотеки Конгресса «Встреча на границах». Когда формировался фонд «Память Америки», было отмечено, что много документов, которые повествуют об истории Аляски, о взаимоотношениях Америки с Дальним Востоком, с Россией в целом хранятся в библиотеках России, их нет в библиотеках Америки. Был разработан специальный проект, в ходе реализации которого было выявлены, оцифрованы и переданы электронные копии соответствующих документов в фонд «Память Америки», тем самым гарантировав ей полноту коллекции «Память Америки». Подробную информацию о проекте «Встреча на границах» можно посмотреть в [16].

Новые свойства библиотек позволяют им работать с широкой читательской аудиторией, разными читательскими группами, индивидуализируя обслуживание. Зарубежными национальными электронными библиотеками накоплен значительный опыт работы с читателями в электронной среде на основе создания сервисов, услуг для целевых групп, который сегодня может быть обобщен методистами и предложен библиотекам для использования в работе в электронной среде. Подробное описание одного из таких модулей см. в публикации [16].

\section{Моделирование электронного краеведческого ресурса в пространстве национальной культуры в электронной среде}

Сегодня в библиотечном деле сложилась такая практика: каждая региональная библиотека создает свой электронный фонд «региональной национальной памяти», в основном, оцифровывая те библиотечные фонды, которые она хранит. Но, представление о «национальной памяти» региона может быть шире, чем фонд одной библиотеки. Источники могут храниться и в других учреждениях культуры, включая федеральные, а также учреждения других регионов или даже стран.

Электронная среда, как уже было сказано выше, позволяет создать целостную коллекцию «национальной памяти» региона, интегрируя ресурсы разных видов и типов из различных учреждений. Для этого, во-первых, необходимо разработать содержательную модель «национальной памяти» региона на основе «репертуара русской книги» [17].

В каждом регионе существует научное сообщество, которое изучает региональную историю и культуру, это, прежде всего, местные университеты, институты региональной истории, краеведческие отделы областных библиотек и другие. Также в создании модели могут принять участие и краеведческие организации региона, а обсуждение модели может быть широко включено в общественный дискурс в регионе.

Таким образом, моделирование образа библиотеки в печатных изданиях из «репертуара русской книги» в электронной среде начинается с представлений, которые сегодня существуют в этой отрасли культуры на местном уровне. Например, «Петербурговедение» - краеведческий ресурс Центральной государственной публичной библиотеки им. В.В. Маяковского имеет большую традицию и богатый опыт обслуживания читателей по истории и культуре СанктПетербурга.

Создание содержательной модели «Петербурговедения», связано с конкретным историческим временем ее создания. А «применительно к общественным наукам любые 
социальные явления не могут получить универсального описания, а должны рассматриваться в определенном конкретно-историческом и социокультурном контексте, который и предопределяет их содержание» $[18$, с.14].

Первым шагом в моделировании ресурса в электронной среде должна быть экспликация понятия «петербурговедение». Экспликация здесь используется как метод углубления, проникновения в понятие «петербурговедение», она позволит выделить те признаки, параметры и характеристики объектов, которые необходимы для построения целостного образа фонда по этой теме в электронной среде. На основе экспликации понятия далее осуществляется разработка концепции электронного ресурса «Петербурговедение». Важным источником в определении книжной составляющей модели может сыграть, в первую очередь, краеведческая библиография и другие виды библиографии.

Второй шаг - разработка концептуальной содержательной модели портала и структуры коллекции. Содержательная концепция и структура позволяют перейти к выявлению источников, которые необходимы для полноты ресурса, в учреждениях культуры города, страны. Те документы, которые уже оцифрованы и находятся в Интернет или на сайтах других библиотек, могут быть представлены в модели ссылками. Использование новых свойств электронной среды, дает возможность собрать комплексный ресурс, то есть различные виды и типы документов в статусе «общественного достояния». Например, моделирование фонда «Петербурговедение» как «национальной памяти» может быть на основе:

- рукописного наследия, «репертуара русской книги» (фонды РНБ, РГБ, БРАН, ГПИБ, региональные фонды областных библиотек и др.);

- архивных (РГИА и др.);

- музейных документов в статусе «общественного достояния» и т.д.

Третий шаг — разработка специальных сервисов и услуг для целевых групп пользователей на основе ресурсов модели петербурговедения.

Четвертый шаг — рецензирование концептуальной содержательной модели и структуры ресурса «Петербурговедение» у ученых Института истории СПбГУ, Института истории РАН, других экспертных сообществ; широкое обсуждение модели портала в пространстве научного, профессионального и общественного дискурса.

Пятый шаг - проектирование. Разработка проекта «Петербурговедение» предполагает описание его для представления властным структурам города для принятия управленческого решения о финансировании и поддержке проекта по сохранению и популяризации культурного наследия города Санкт-Петербурга.

Проект предполагает его реализацию как «общественного блага», то есть для реализации проекта «Петербурговедение» как краеведческого ресурса необходимо решение «Комитета по культуре Санкт-Петербурга», который осуществляет финансирование и правовой доступ к ресурсам учреждений культуры, электронные копии документов которых войдут в проект.

Есть уверенность, что такой город как Санкт-Петербург - культурная столица России сможет реализовать проект достойный его славной истории. Проект «Петербурговедение» может стать той моделью, которая будет реализована и в регионах России на основе областных краеведческих коллекций, представив национальное наследие, национальную память для россиян. Слова о том, что национальная культура является фактором национальной безопасности, будут подтверждены действиями, национальная память будет представлена в электронной среде, то есть станет доступной для всех граждан России. 


\section{Литература}

[1] Пелипенко А. А. Интернет как феномен эволюции культуры // Власть. 2015. № 1. С.164-169. - Режим доступа: http://jour.isras.ru/index.php/vlast/article/view/1564/1541 (дата обращения: 25.02.2021).

[2] Путин В.В. Послание Президента Федеральному Собранию 1 марта 2018 года: стенограмма - Режим доступа: http://kremlin.ru/events/president/news/56957 (дата обращения: 25.02.2021)

[3] Костина А. В., Макаревич Э. Ф., Карпухин О. И., Луков В. А. Культура как фактор национальной безопасности современной России: значение и ролевая модель: проект исследования М.: УРСС, 2020. 16 c. - Режим доступа: https://www.mosgu.ru/science/ifpi/priority-research-areas/National-Security.pdf.

[4] Указ Президента Российской Федерации от 31 декабря 2015 г. № 683 «О Стратегии национальной безопасности Российской Федерации» [Электронный ресурс] // Информационно-правовой «ГАРАНТ.РУ». - Режим доступа: http://base.garant.ru/71296054/ (дата обращения: 25.07.2020).

[5] Ноам Хомский «Какие принципы и ценности управляют миром?» // Режим доступа: https://vk.com/video55155418 456239691 (дата обращения: 25.02.2021).

[6] Миронов В. В. Трансформация культуры в пространстве глобальной коммуникации // Гуманитарий Юга России, 2012. № 1. С. 101-120. Режим доступа: https://www.isras.ru/files/File/Gumanitary_Yuga_Rossii/2012_1/Mironov.pdf (дата обращения: 25.02.2021).

[7] Когнитивные науки. Истории из будущего с М. Ковальчуком, 15.01.2012 г. - Режим доступа: https://www.youtube.com/watch?v=GS7IaWVysFE (дата обращения: 25.02.2021).

[8] Цифровизация в сфере культуры. Законодательство и правоприменительная практика: рекомендации парламентских слушаний, 13 февраля 2018 г.- Режим доступа: http://prodod.moscow/wpcontent/uploads/2018/04/29.03.2018_01-49_01-3520_18_Govoruhin_S.S._Pravitelstvo_Moskvy-1.pdf (дата обращения: 25.02.2021)

[9] «Знания - результат познания действительности $<\ldots>$, её отражение в сознании человека в виде представлений, понятий, суждений, теорий...» // Знание. Словари и энциклопедии на Академике Режим доступа: https://academic.ru/searchall.php?SWord=\%D0\%B7\%D0\%BD\%D0\%B0\%D0\%BD\%D0\%B8\%D0\%B5\&from $=\mathrm{xx} \&$ to=ru\&did=\&stype = (дата обращения: 25.02 .2021$)$.

[10]Миронов Владимир. Трансформация культуры в пространстве глобальной коммуникации // Гуманитарий Юга России, 2012. № 1. С. 101-120. - Режим доступа: https://www.isras.ru/files/File/Gumanitary_Yuga_Rossii/2012_1/Mironov.pdf (дата обращения: 25.02.2021). (дата обращения: 25.02.2021).

[11]Переслегин Сергей. Книга будущего: выступление на международной футурологической конференции «Книга будущего: авторские права и пиратство в XXII веке» (Президентская библиотека): - Режим доступа: https://www.youtube.com/watch?v=amA7za5gFxw (дата обращения: 5.03.2021).

[12] «Ноам Хомский: какие принципы и ценности управляют миром?» - Режим доступа: https://vk.com/video-55155418 456239691 (дата обращения: 25.07.2020).

[13] Социальный институт - это исторически сложившаяся, устойчивая форма организации совместной деятельности людей, реализующих определенные функции в обществе, главная из которых удовлетворение социальных потребностей общества. Решения по развитию социальных институтов принимаются в рамках государственной политики. Каждый социальный институт характеризуется наличием цели деятельности и конкретными функциями, обеспечивающими ее достижение $/ /$ - Режим доступа: https://www.grandars.ru/college/sociologiya/socialnye-instituty.html (дата обращения: 25.07.2020).

[14] Смолина Е.В. Новые свойства библиотек в электронной среде // Национальная библиотека. 2015. № 2(05). С.40-43. - Режим доступа: https://vivaldi.nlr.ru/pm000000592/details\#page= (дата обращения: 25.07.2020).

[15] Meeting of Frontiers // Режим доступа: http://frontiers.loc.gov/intldl/mtfhtml/mfhome.html (дата обращения: 25.07.2020).

[16] Акилина М.И., Смолина Е.В. Обучение с использованием первоисточников - интеграция библиотек в образовательную среду: зарубежный опыт // Методика и практика использования национальных электронных ресурсов в образовательной деятельности: Науч. ред. П.В. Федоров. - СПб., 2017. С.58-80 (Сборники Президентской библиотеки. Серия «Электронный архив». - Вып. 2). - Режим доступа: https://www.prlib.ru/item/708595 (дата обращения: 5.03.2021).

[17]Ермолаева М.А. Репертуар русской книги. История, теория и методика создания: автореферат диссертации на соискание ученой степени к.филол.н. - М., 1996. 16 с.

[18]Доровских Е.М. Культура как фактор национальной безопасности: правовые аспекты // Журнал российского права. 2009. № 12. С.14-21. 


\title{
Digital Local Studies: Modeling of the National Regional Heritage of Libraries in the Electronic Environment (on the Example of the "Petersburg Studies" Fund)
}

\author{
E.V. Smolina
}

Presidential Library, Russia

\begin{abstract}
Annotation: the article outlines the problems of mastering the electronic environment by libraries, emphasizes the lack of scientific research to obtain convergent knowledge as the basis for making managerial decisions in librarianship to create electronic collections of "national memory". A modeling method is proposed as one of the ways to represent the national regional heritage in the electronic environment. Modeling is built taking into account the new properties of libraries in the electronic environment. The modeling is based on the "repertoire of the Russian book". The logic of modeling is shown on the example of the "Petersburg Studies" foundation.
\end{abstract}

Key words: digital study of local lore, modeling, Petersburg studies, electronic environment, regional heritage of libraries, convergent knowledge, culture as a factor of national security.

\section{References}

[1] Pelipenko A. A. Internet as a phenomenon of the evolution of culture // Power. 2015. No. 1. P.164-169. Access mode: http://jour.isras.ru/index.php/vlast/article/view/1564/1541 (date of access: 25.07.2021).

[2] Putin V.V. President's message to the Federal Assembly on March 1, 2018: transcript - Access mode: http://kremlin.ru/events/president/news/56957 (date of access: 25.02.2021)

[3] Kostina A. V., Makarevich E. F., Karpukhin O. I., Lukov V. A. Culture as a factor of national security in modern Russia: significance and role model: research project Moscow: URSS, 2020. - 16 p. ... - Access mode: https://www.mosgu.ru/science/ifpi/priority-research-areas/National-Security.pdf.

[4] Decree of the President of the Russian Federation of December 31, 2015 No. 683 "On the National Security Strategy of the Russian Federation" [Electronic resource] // Information and legal "GARANT.RU". - Access mode: http://base.garant.ru/71296054/ (date of access: 25.02.2021).

[5] Noam Chomsky "What principles and values rule the world?" // Access mode: https://vk.com/video55155418_456239691 (date of access: 25.02.2021).

[6] Mironov VV Transformation of culture in the space of global communication // Humanitarian of the South of Russia, 2012. No. $\quad$ N. $\quad$ P. $101-120 . \quad$ Access mode: https://www.isras.ru/files/File/Gumanitary_Yuga_Rossii/2012_1/Mironov.pdf (date of access: 25.02.2021).

[7] Cognitive Sciences. Stories from the future with $\bar{M}$. Kovalchuk, 15.01.2012 - Access mode: https://www.youtube.com/watch?v=GS7IaWVysFE (date of access: 25.02.2021).

[8] Digitalization in the field of culture. Legislation and Law Enforcement Practice: Recommendations of Parliamentary Hearings, February 13, 2018 - Access mode: http://prodod.moscow/wpcontent/uploads/2018/04/29.03.2018_01-49_01-3520_18_Govoruhin_S.S._Pravitelstvo_Moskvy-1. pdf (date accessed: 25.02 .2021 )

[9] "Knowledge is the result of cognition of reality $<\ldots>$, its reflection in human consciousness in the form of ideas, concepts, judgments, theories ..."// Knowledge. Dictionaries and encyclopedias on the Academician - Access mode:

https://academic.ru/searchall.php?SWord=\%D0\%B7\%D0\%BD\%D0\%B0\%D0\%BD\%D0\%B8\%D0\%B5\&from $=\mathrm{xx} \&$ to $=$ ru\&did $=\&$ stype $=($ date of access: 25.02 .2021$)$.

[10] Mironov Vladimir. Transformation of culture in the space of global communication // Humanitarian of the South of Russia, 2012. No. 1. P. 101-120. - Access mode: https://www.isras.ru/files/File/Gumanitary_Yuga_Rossii/2012_1/Mironov.pdf (date of access: 25.02.2021). (date of access: 25.02.2021).

[11] Pereslegin Sergey. The Book of the Future: Speech at the International Futurological Conference "The Book of the Future: Copyright and Piracy in the XXII Century" (Presidential Library): - Access mode: https://www.youtube.com/watch?v=amA7za5gFxw (date accessed: 5.03. 2021).

[12] "Noam Chomsky: what principles and values rule the world?" - Access mode: https://vk.com/video55155418_456239691 (date of access: 25.02.2021). 
[13] A social institution is a historically developed, stable form of organizing joint activities of people who perform certain functions in society, the main of which is meeting the social needs of society. Decisions on the development of social institutions are made within the framework of state policy. Each social institution is characterized by the presence of a goal of activity and specific functions that ensure its achievement // - Access mode: https://www.grandars.ru/college/sociologiya/socialnye-instituty.html (date of access: 25.07.2020).

[14] Smolina E.V. New properties of libraries in the electronic environment // National Library. 2015. No. 2 (05). S.40-43. - Access mode: https://vivaldi.nlr.ru/pm000000592/details\#page= $($ date of access: 25.07.2021).

[15] Meeting of Frontiers // Access mode: http://frontiers.loc.gov/intldl/mtfhtml/mfhome.html (date accessed: 25.02.2021).

[16] Akilina M.I., Smolina E.V. Learning using primary sources - the integration of libraries into the educational environment: foreign experience // Methodology and practice of using national electronic resources in educational activities: Scientific. ed. P.V. Fedorov. - SPb., 2017. P.58-80 (Collections of the Presidential Library. Series "Electronic Archive". - Issue 2). - Access mode: https://www.prlib.ru/item/708595 (date of access: 03/05/2021).

[17] Ermolaeva M.A. The repertoire of the Russian book. History, theory and a creation technique: the dissertation author's abstract on scientific degree competition k.filol.n. - M., 1996.16 p.

[18] Dorovskikh E.M. Culture as a factor of national security: legal aspects // Journal of Russian law. 2009. No. 12. P.14-21. 